\title{
Seasonal incidence of scale insects, whiteflies and psyllids (Hemiptera) of olive and their natural enemies in Egypt
}

\author{
Shaaban Abd-Raboou and Noha Ahmed \\ Plant Protection Research Institute, Agricultural Research Center, Dokki, Giza, Egypt.
}

ABSTRACT

Scale insects, whiteflies and psyllids (Hemiptera) are the main olive pests in Egypt. The aim of this work is to study the incidence of scale insects, whiteflies and psyllids and their natural enemies on olive trees in different locations in Egypt during 2009-2010. The results of the present work indicated that the seasonal abundance of Lucaspis riccae Targioni-Tozzetti (Hemiptera: Diaspididae) on olive trees reached maximum during November and February in first and second years, respectively. Percent parasitism by Aphytis libanicus Traboulsi (Hymenoptera: Aphelinidae) reached maximum during December with percent parasitism 11.1 and $12.2 \%$, during the two years under considerations, respectively. The insect population of Parlatoria oleae Leonardi (Hemiptera: Diaspididae) reached maximum during October, 20092010. Percent parasitism by Aphytis lingnanensis Compere (Hymenoptera: Aphelinidae) and Habrolepis aspidioti Compere and Annecke (Hymenoptera: Encyrtidae) reached maximum during December and November with percent parasitism 6.5 and 12.5 in the first year, respectively and in November in the second year with percent parasitism 6.9 and $14.2 \%$, respectively. The predator Chilocorus bipustulatus L. (Coleoptera: Coccinellidae) reached maximum during February and March in the first and second years, respectively. In this work the abundance of Saissetia coffeae (Walker) (Hemiptera: Coccidae) reached maximum during October in the first and second years. Percent parasitism by Metaphycus flavus (Howard) (Hymenoptera: Encyrtidae) reached maximum during October and September with parasitism rates 11.5 and $13.5 \%$ during the first and second years, respectively. The predator Scymnus syriacus (Marseul) (Coleoptera: Coccinellidae) reached maximum during October in the first and second years. The populations of Saissetia oleae (Bernard) (Hemiptera: Coccidae) reached maximum during October in the first and second years. Percent parasitism of Metaphycus lounsburyi (Howard) (Hymenoptera: Encyrtidae) reached maximum during October during the first and second years, with percent parasitism 34.2.1 and $40.1 \%$ respectively. The predator Exochomus flavipes (Thunberg) (Coleoptera: Coccinellidae) reached maximum during October in the first and second years. The seasonal abundance of Aleurolobus olivinus Silvestri (Hemiptera: Aleyrodidae) reached maximum during April in first and second years. Percent parasitism by Encarsia olivina (Masi) (Hymenoptera: Aphelinidae) reached maximum during April during the first and second years with percent parasitism 0.6 and 0.5 , respectively. The abundance of Siphoninus phillyreae (Haliday) (Hemiptera: Aleyrodidae) reached maximum during October in first and second years, respectively. Percent parasitism by Encarsia inaron (Walker), (Hymenoptera: Aphelinidae) reached maximum during October in first and second years with percent parasitism 1.8 and $2.9 \%$, respectively. The results of the present study indicated that the seasonal abundance of Euphyllura straminae Loginova (Hemiptera: Psyllidae) reached maximum during March in the first and second years. The predator Orius sp. reached maximum during March in the first and second years. 


\section{INTRODUCTION}

Scales insects (Hemiptera: Coccoidea) and some other species excrete honeydew, sticky liquid produced by sucking insects that ingest large quantities of plant sap. Sticky honeydew and the blackish sooty mold growing on honeydew can bother people even when scale populations are not harming plants. When plants are heavily infested with scales insects, leaves may look wilted, turn yellow, and drop prematurely. Scale insects sometimes result in curl leaves or cause deformed blemishes or discolored halos in fruit, leaves, or twigs. Bark infested with armored scales may crack and exude gum. Certain armored scales also feed on fruit, but this damage is often just aesthetic. Soft scales (Hemiptera: Coccidea) infest leaves and twigs but rarely feed on fruit. A major concern with soft scales is their excretion of abundant honeydew, which contaminates fruit, leaves, and surfaces beneath plants. Honeydew encourages the growth of black sooty mold and attracts ants, which in turn protect scales from natural enemies. When found in numerous abundance, some scale species weaken plants and cause them to grow slowly. Branches or other plant parts may die if they remain heavily infested with scales. If plant parts die quickly, dead brownish leaves may remain on branches, giving them a scorched appearance. Several years of severe infestations may kill young plants. Certain armored scales may be more likely to kill plants. Soft scales reduce plant vigor, but seldom kill trees or shrubs (Gill, 1997). Surveys of scale insects attacking olive trees in Egypt have been conducted by many researchers and scientists, e.g., Ezzat (1957), Amin (1966), Moursi and Mesbah (1985), Hamza (1975), Amin and Saleh (1975), El-Hakim and Helmy (1982), Moursi and Hegazi (1983) and later Abd-Rabou (2001b, 2003b and 2008). El-Hakim and Helmy (1982) recorded four and three generations for Lucaspis riccae Targioni-Tozzetti and Parlatoria oleae Leonardi (Hemiptera: Diaspididae), respectively. Solaiman (1970) stated that the Triona oil $(2 \%)$ or Malathion $(0.3 \%)$ gave satisfactory results to control $P$. oleae. Parasitic wasps are often the most important natural enemies of scales. Parasitoids include many species of Aphytis, Coccophagus, Encarsia (Hymenoptera: Aphelinidae) and Metaphycus (Hymenoptera: Encyrtidae). Predatory Chilocorus, Hyperaspis, and Rhyzobius (Coleoptera: Coccinellidae) species lady beetles (ladybugs) can easily be overlooked because many are tiny, colored and shaped like scales, or feed beneath scales (Gill, 1997).

Whiteflies (Hemiptera: Aleyrodoidea) injure olive plants by consuming large quantities of sap, which it obtains with its sucking mouth parts. Further indirect injury is caused by sooty mold fungus which grows over fruit and foliage in the copious amount of honeydew excreted by the whitefly. This black fungus may cover the leaves and fruit so completely that it interferes with the proper physiological activities of the trees. Heavily-infested trees become weak and produce small crops of insipid fruit. Only three species of whiteflies have been recorded attacking olive trees in Egypt. These are Aleurolobus olivinus (Silvestri) (Abd-Rabou, 1996), Bemisia tabaci (Gennadius) (Abd-Rabou, 1997) and Siphoninus phillyreae (Haliday) (Hemiptera: Aleyrodidae) (Abd-Rabou, 2003a). Insecticidal soaps or oils such as neem oil may reduce but not eliminate the populations of whiteflies (Abd-Rabou,2003a). Psyllids (Hemiptera : Psyllidoidea) on olive causes severe damage to olive trees. The 2nd generation, being associated with new flowering and fruiting olive branches, is the most harmful not only because of the direct feeding activity affected yield, but also because indirect action by producing waxy secretions induces many of the flowers to abort, even those not attacked directly. The presence of honeydew and sooty molds aggravate the latter situation. Psyllids suck plant juices. Some secrete a white wax and 
all produce honeydew, sometimes in palletized or crystallized form, on which blackish sooty mold grows. High psyllid populations reduce plant growth or cause terminals to distort, discolor, or die back. High populations of certain species, such as olive psyllid, can cause defoliation. A few species cause galls on leaves or buds, for example when psyllid feeding causes the plant to form a pit around where each nymph settles. Early damage typically occurs on young foliage where most eggs are laid. The olive psyllid, Euphyllura straminae Loginova (Hemiptera: Psyllidae) is an economic important insect pest on olive trees in Egypt (Abd-Rabou, 2008). Most native species of psyllids require no management. Even when populations are abundant, plants can tolerate substantial feeding and psyllid populations will decline naturally (Dreistadt et al., 1994).

The aim of this work is to study the incidence of scale insects, whiteflies and psyllids and their natural enemies on olive trees in different locations in Egypt.

\section{MATERIALS AND METHODS}

Abundance of the populations of scale insects, whiteflies and psyllids and their natural enemies were carried out on olive trees during 2009 and 2010 in El-Arish, Ismailia, Fayoum, Northern Coast. The plant areas selected for these investigations received no chemical control measures for several years. Twenty trees almost similar in age, size, shape and growth condition were randomly chosen for sampling at a month intervals for each location. On each sampling, 60 leaves and 15 twigs (20 cm.long) were chosen at random. Thereafter, the leaves and twigs were kept in a closed paper bags and transferred to the laboratory for further examination and counting. Each leaf was stored in a well-ventilated emergence glass tube and monitored daily for parasitoid emergence. Rate of parasitism was determined by dividing the number of emerging parasitoid from each by the number of hosts existing. Predators was counted in filed and transferred to the laboratory for further examination.

Simple correlation and regression values were calculated to obtain information about the relationships between the three tested weather factors and the population of the pest and its natural enemies.

\section{RESULTS AND DISCUSSION}

1. Population dynamics of the olive scale, Lucaspis riccae and its parasitoid Aphytis libanicus on olive trees in Fayoum Governorate

The seasonal abundance of the olive scale, L.riccae was studied for two successive years from 2009-2010 on olive trees. The obtained results in Figs (1 and 2) showed that, the insect population reached maximum during November (2250/ 60 leaves and 15 twigs) in first year and February (1021/ 60 leaves and 15 twigs) in the second year. Percent parasitism by Aphytis libanicus Traboulsi (Hymenoptera: Aphelinidae) reached maximum at December during the first and second years (11.1 and 12.2 / 60 leaves and 15 twigs, respectively).

Statistical analysis showed that the simple correlation between the population of parasitoid, A. libanicus, maximum and minimum temperature and the mean number of the olive scale, $L$. riccae were significant $(\mathrm{r}=0.67,0.81$ and 0.72$)$, respectively and non-significant $(\mathrm{r}=0.33)$ between relative humidity and the mean number of the olive scale during the 2009 year. Also, statistical analysis showed that the simple regression for changing the population of parasitoid, maximum and minimum temperature on the 
mean number of the olive scale were significant or highly significant $(b=0.71,0.92$ and 0.66$)$ and non-significant $(b=0.25)$ between relative humidity and the mean number of the olive scale during the 2009 year. In 2010 statistical analysis showed that the simple correlation between the population of parasitoid, maximum and minimum temperature and the mean number of the olive scale, L. riccae were significant or highly-significant $(\mathrm{r}=0.82,0.95$ and 0.85$)$, respectively and nonsignificant $(\mathrm{r}=0.04)$ between relative humidity and the mean number of the olive scale. Also, statistical analysis showed that the simple regression for changing the population of parasitoid, maximum and minimum temperature on the mean number of the olive scale were significant $(b=0.65,0.88$ and 0.71$)$ and non-significant $(b=0.05)$ between relative humidity and the mean number of the olive scale.

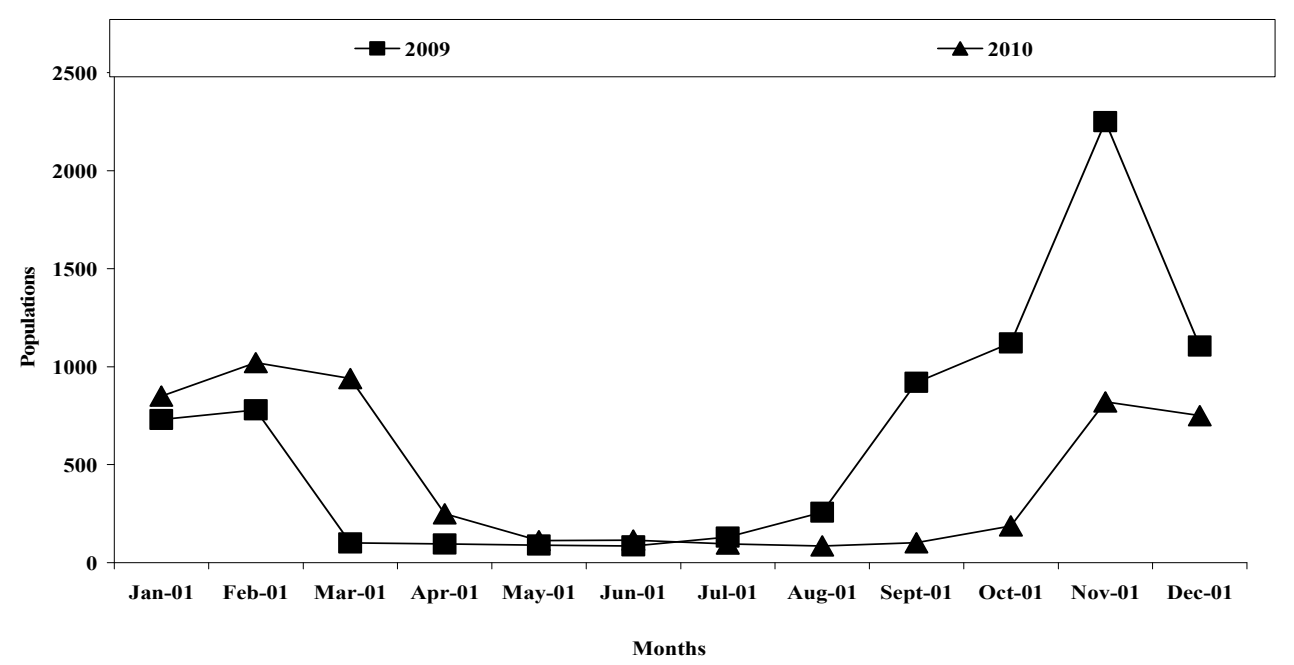

Fig. 1: Population dynamics of the olive scale, Lucaspis riccae on olive trees in Fayoum Governorate

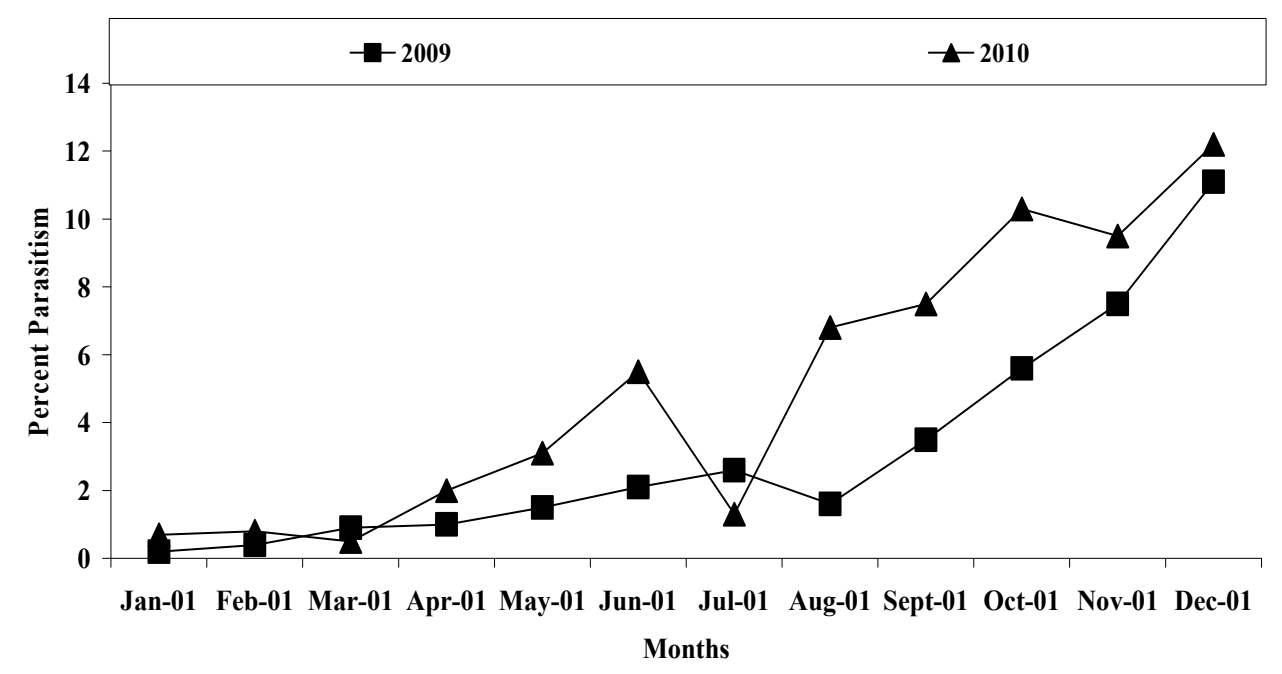

Fig. 2: Percent parasitism by the parasitoid, Aphytis libanicus associated with the olive scale, Lucaspis riccae on olive trees in Fayoum Governorate

2. Population dynamics of the parlatoria scale, Parlatoria oleae and its natural enemies on olive trees in Ismailia Governorate.

The seasonal abundance of the parlatoria scale, $P$. oleae was studied for two successive years from 2009-2010 on olive trees .The obtained results in Figs ( 3 and 4) 
showed that, the insect population reached maximum during October (3500 and 2116/ 60 leaves and 15 twigs) in first and second years, respectively. Percent parasitism by Aphytis lingnanensis Compere (Hymenoptera: Aphelinidae) and Habrolepis aspidioti Compere and Annecke (Hymenoptera: Encyrtidae) reached maximum during December and November during the first (6.5 and 12.5 / 60 leaves and 15 twigs, respectively) and during November in the second years (6.9 and 14.2/ 60 leaves and 15 twigs, respectively). While the predator Chilocorus bipustulatus L. (Coleoptera: Coccinellidae) reached maximum during February and March in the first and second years (6 and 12 individuals / 60 leaves and 15 twigs, respectively).

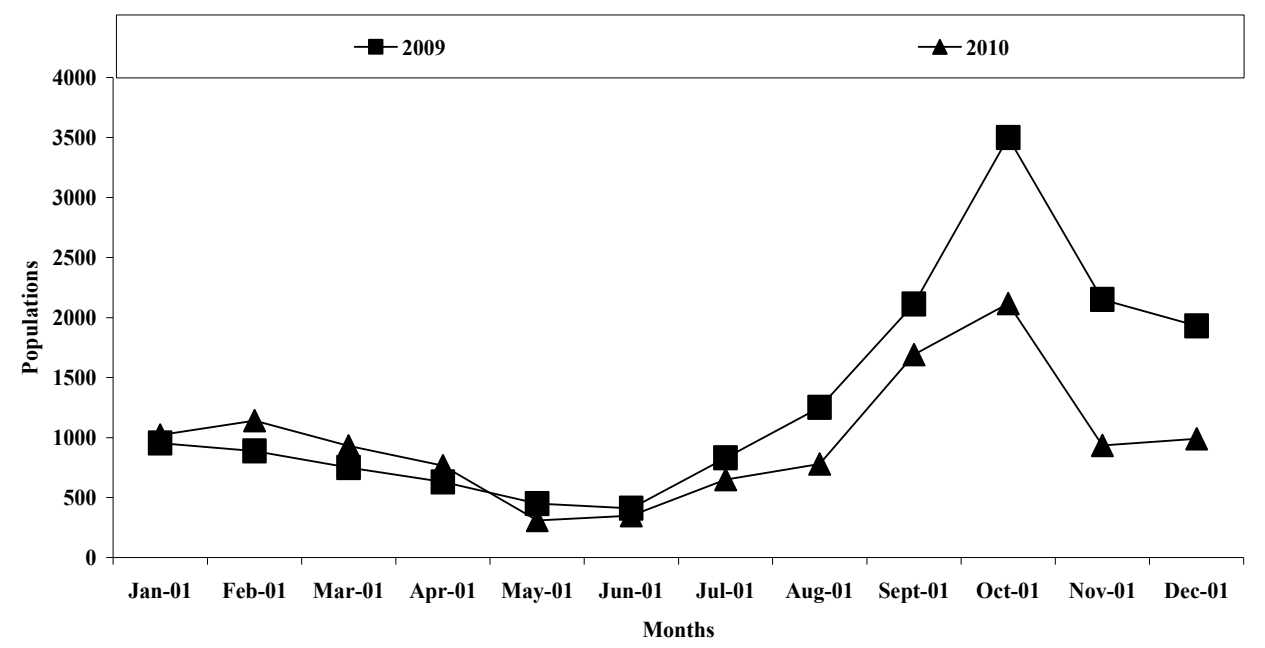

Fig. 3: Population dynamics of the parlatoria scale, Parlatoria oleae on olive trees in Ismailia Governorate

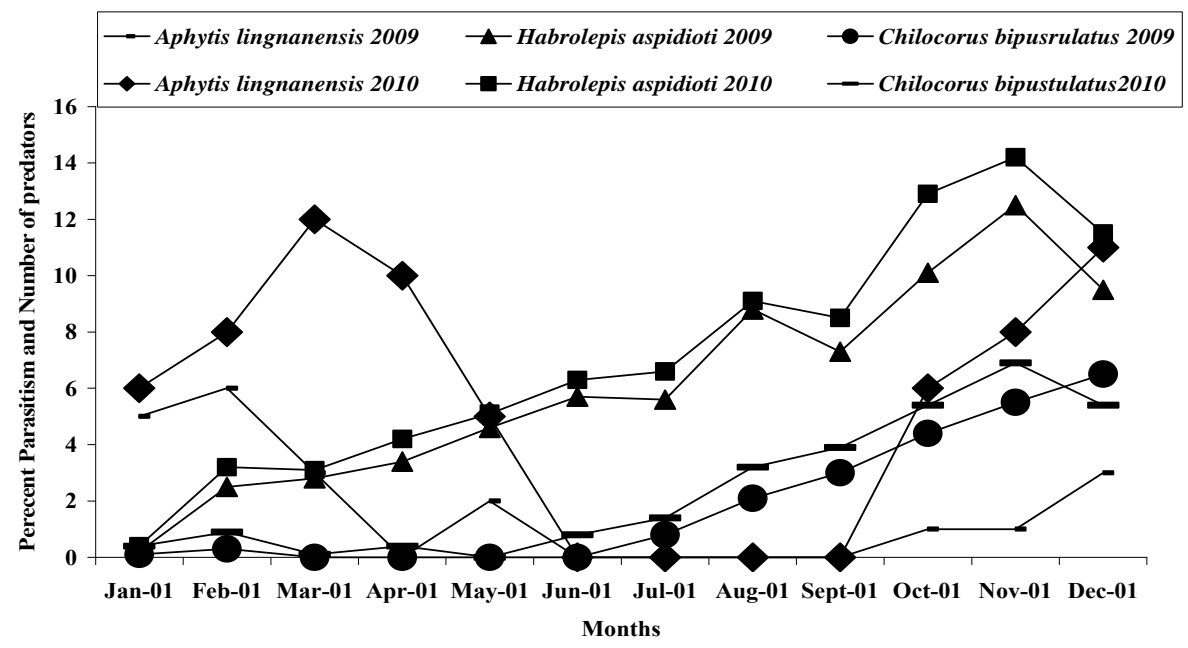

Fig. 4: Percent parasitism by different parasitoids and predator associated with the parlatoria scale, Parlatoria oleae on olive trees in Ismailia

Statistical analysis showed that the simple correlation between the population of parasitoids and predator (A. lingnanensis, H. aspidioti, C. bipustulatus), relative humidity and the mean number of the parlatoria scale, $P$. oleae were non-significant $(\mathrm{r}=0.54,0.41,0.63$ and 0.29$)$, respectively and significant $(\mathrm{r}=0.84$ and 0.75$)$ between maximum and minimum temperature and the mean number of the parlatoria scale during the 2009 year. Also, statistical analysis showed that the simple regression for changing the population of parasitoids (A. lingnanensis, $H$. aspidioti, $C$. bipustulatus), relative humidity and the mean number of the parlatoria scale, $P$. oleae 
were non-significant $(\mathrm{r}=0.31,0.28,0.55$ and 0.36$)$, respectively and significant $(\mathrm{r}=$ 0.91 and 0.83 ) between maximum and minimum temperature and the mean number of the parlatoria scale during the 2009 year. In 2010, statistical analysis showed that the simple correlation between the population of parasitoids and predator (A. lingnanensis, $H$. aspidioti, $C$. bipustulatus) and the mean number of the parlatoria scale, $P$. oleae were non-significant $(\mathrm{r}=0.32,0.09$, and 0.52$)$, respectively and significant or highly-significant $(\mathrm{r}=0.93,0.86$ and 0.62$)$ between maximum and minimum temperature, relative humidity and the mean number of the parlatoria scale. Also, statistical analysis showed that the simple regression for changing the population of parasitoids and predator (A. lingnanensis, H. aspidioti, C. bipustulatus), and the mean number of the parlatoria scale, $P$. oleae were non-significant $(\mathrm{r}=0.26$, 0.33 and 0.41$)$, respectively and significant $(r=0.91$ and 0.83$)$ between maximum and minimum temperature, relative humidity and the mean number of the parlatoria scale.

\section{Population dynamics of the olive whitefly, Aleurolobus olivinus and its parasitoid, Encarsia olivina on olive trees in El-Arish Governorate}

The seasonal abundance of the olive whitefly, A. olivinus was studied for two successive years from 2009-2010 on olive trees .The obtained results in Figs (5 and 6) showed that, the insect population reached maximum during April (560 and 480/ 60 leaves and 15 twigs) in first and second years, respectively. Percent parasitism by Encarsia olivina (Masi) (Hymenoptera: Aphelinidae) reached maximum during April during the first and second years (0.6 and 0.5\%/ 60 leaves and 15 twigs, respectively).

Statistical analysis showed that the simple correlation between maximum and minimum temperature and the mean number of the olive olive whitefly, A. olivinus were significant or highly significant $(\mathrm{r}=0.81,0.72$ and 0.33$)$, respectively and nonsignificant $(\mathrm{r}=0.29)$ between the population of parasitoid (E. olivina) and the mean number of the olive whitefly during the 2009 year. Also, Statistical analysis showed that the simple regression for changing the population of parasitoid on the mean number of the olive whitefly were non-significant $(b=0.35)$ and significant $(b=0.92$, 0.66 and 0.21 ) between maximum and minimum temperature and relative humidity and the mean number of the olive whitefly during the 2009 year. In 2010, statistical analysis showed that the simple correlation between maximum and minimum temperature, relative humidity and the mean number of the olive whitefly, A. olivinus were significant $(\mathrm{r}=0.84,0.69$ and 0.48$)$, respectively and non-significant $(\mathrm{r}=0.31)$ between the population of parasitoid and the mean number of the olive whitefly. Also, Statistical analysis showed that the simple regression for changing the population of parasitoid on the mean number of the olive whitefly were non-significant $(b=0.29)$ and significant $(b=0.98,0.71$ and 0.54$)$ between maximum and minimum temperature and relative humidity and the mean number of the olive whitefly. 


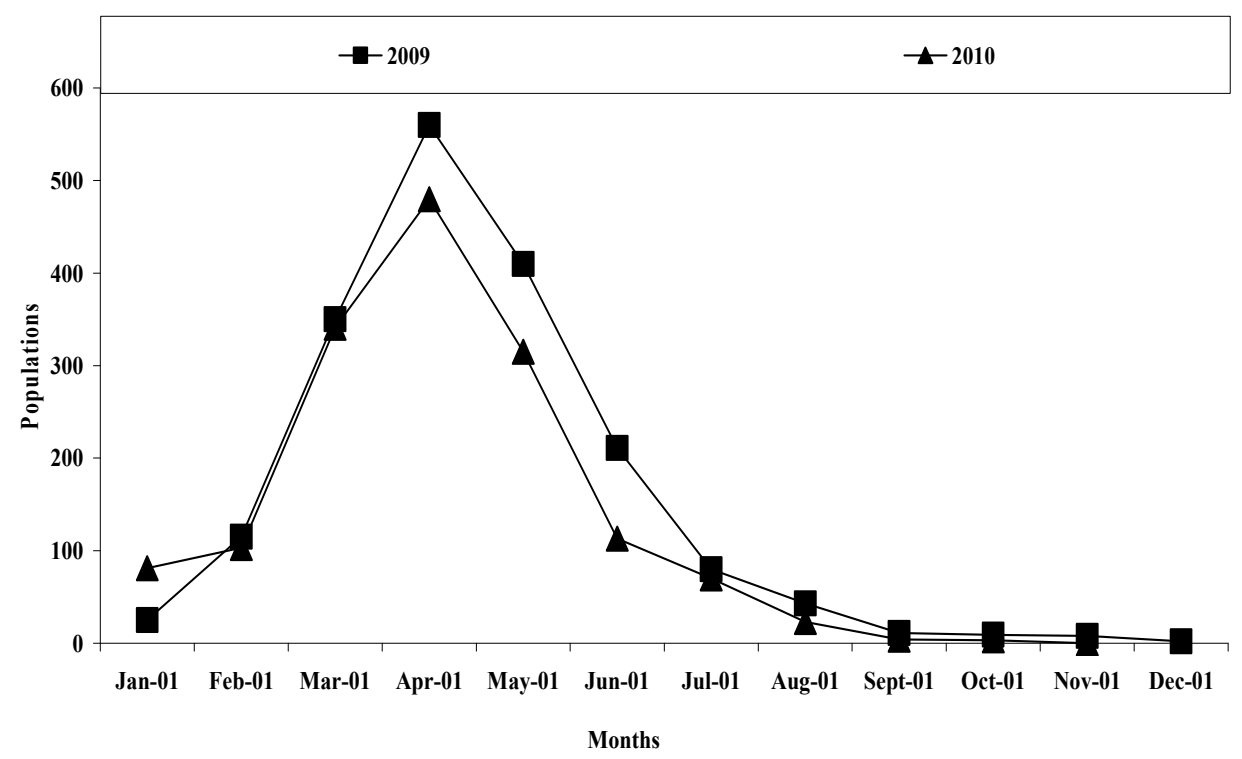

Fig. 5: Population dynamics the olive whitefly, Aleurolobus olivinus on olive trees in El-Arish Governorate.

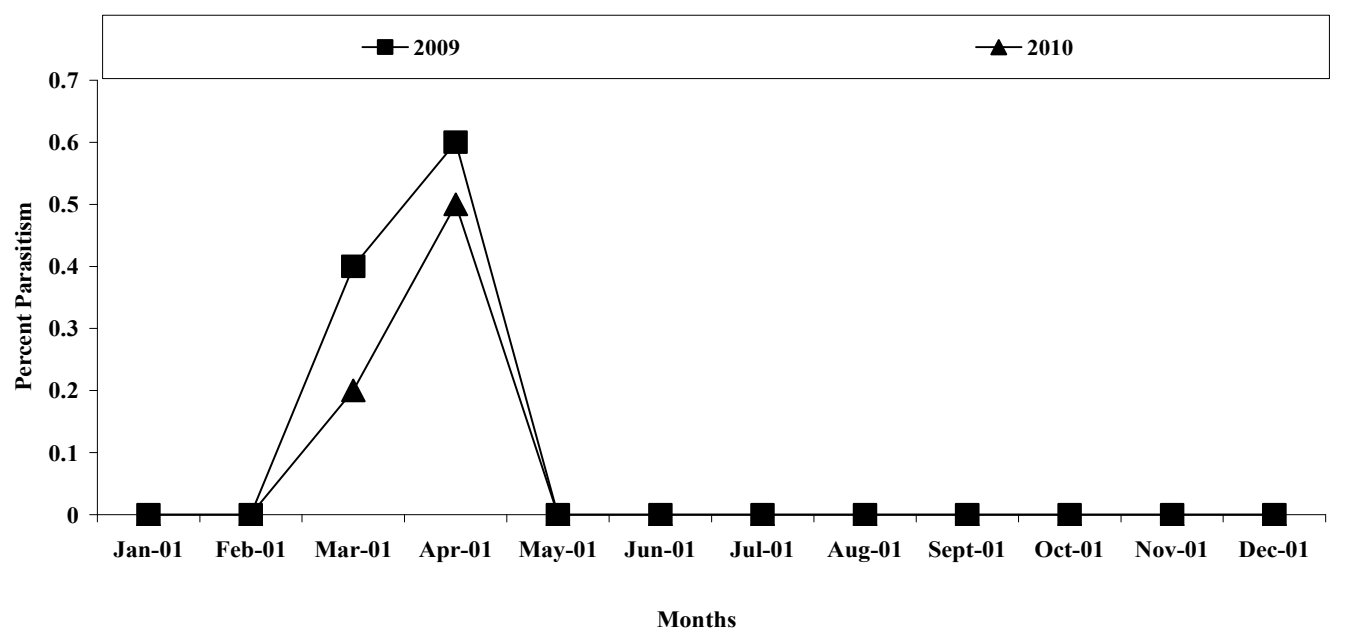

Fig. 6: Percent parasitism by the parasitoid, Encarsia olivina associated with the olive whitefly, Aleurolobus olivinus on olive trees in El-Arish Governorate

\section{Population dynamics of the whitefly, Siphoninus phillyreae and its parasitoid} Encarsia inaron on olive trees in Fayoum Governorate

The seasonal abundance of the whitefly, S. phillyreae was studied for two successive years from 2009-2010 on olive trees .The obtained results in Figs (7 and 8) showed that, the insect population reached maximum during October (1320 and 1817/ 60 leaves and 15 twigs) in first and second years, respectively. Percent parasitism by Encarsia inaron (Walker), (Hymenoptera: Aphelinidae) reached maximum during October in first and second years (1.8 and 2.9\% / 60 leaves and 15 twigs, respectively).

Statistical analysis showed that the simple correlation between maximum, minimum temperature, relative humidity and the mean number of the whitefly, S.phillyreae were significant or highly-significant $(\mathrm{r}=0.92,0.81$ and 0.41$)$, respectively and non-significant $(\mathrm{r}=0.26)$ between the population of parasitoid, and the mean number of the whitefly during the 2009 year. Also, statistical analysis 
showed that the simple regression for changing maximum, minimum temperature, relative humidity and the mean number of the whitefly, S. phillyreae were significant or highly-significant $(b=0.97,0.79$ and 0.46$)$, respectively and non-significant $(b=$ 0.33 ) between the population of parasitoid, and the mean number of the whitefly during the 2009 year. In 2010, statistical analysis showed that the simple correlation between maximum, minimum temperature, and the mean number of the whitefly, $S$. phillyreae were significant or highly-significant $(\mathrm{r}=0.88$ and 0.73$)$, respectively and non-significant $(\mathrm{r}=0.31$ and 0.34$)$ between the population of parasitoid, relative humidity and the mean number of the whitefly during the 2010 year. Also, statistical analysis showed that the simple regression for changing maximum, minimum temperature, and the mean number of the whitefly, S. phillyreae were significant or highly-significant $(b=0.93$ and 0.84$)$, respectively and non-significant $(b=0.35$ and 0.27 ) between the population of parasitoid, relative humidity and the mean number of the whitefly.

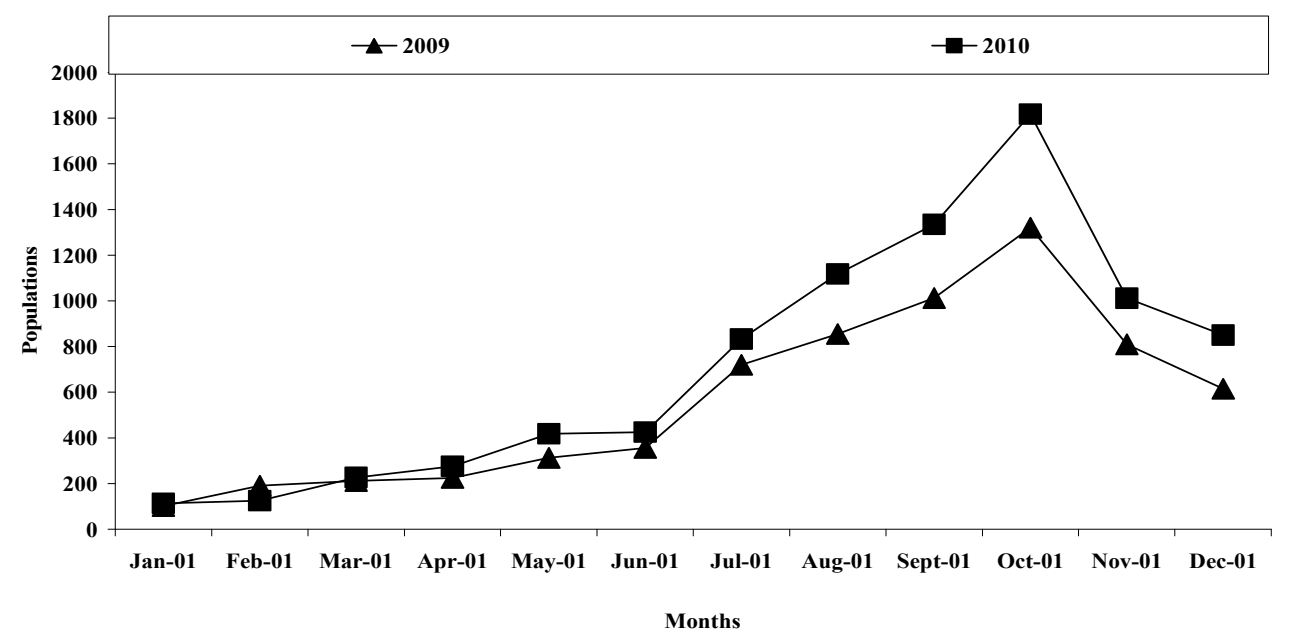

Fig. 7: Population dynamics of the whitefly, Siphoninus phillyreae on olive trees in Fayoum Governorate

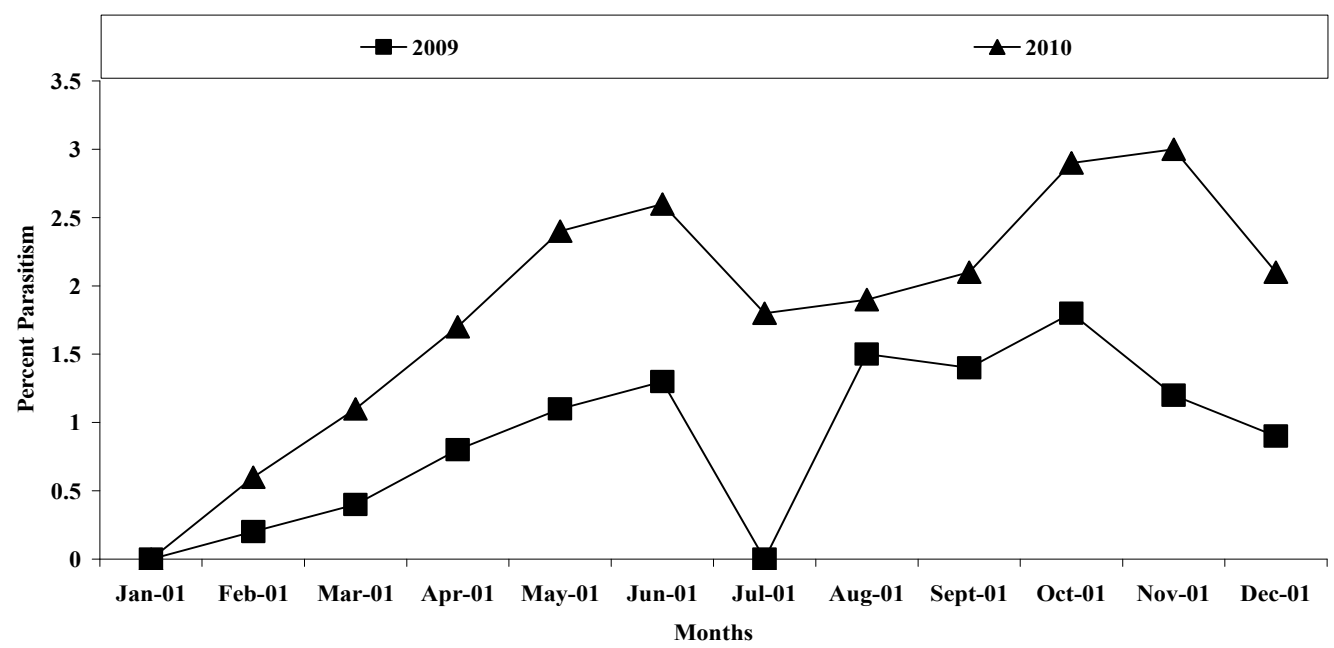

Fig. 8: Percent parasitism by the parasitoid, Encarsia inaron associated with the whitefly, Siphoninus phillyreae on olive trees in Fayoum Governorate 


\section{Population dynamics of the psyllid, Euphyllura straminea and its predator, Orius sp. on olive trees in Fayoum Governorate.}

The seasonal abundance of the psyllid, Eu. straminea was studied for two successive years from 2009-2010 on olive trees. The obtained results in Figs (9 and 10) showed that, the insect population reached maximum during March (1350 and 1488/ 60 leaves and 15 twigs) in the first and second years, respectively. The predator Orius sp. reached maximum during March in the first and second years (20 and 33 individuals / 60 leaves and 15 twigs, respectively).
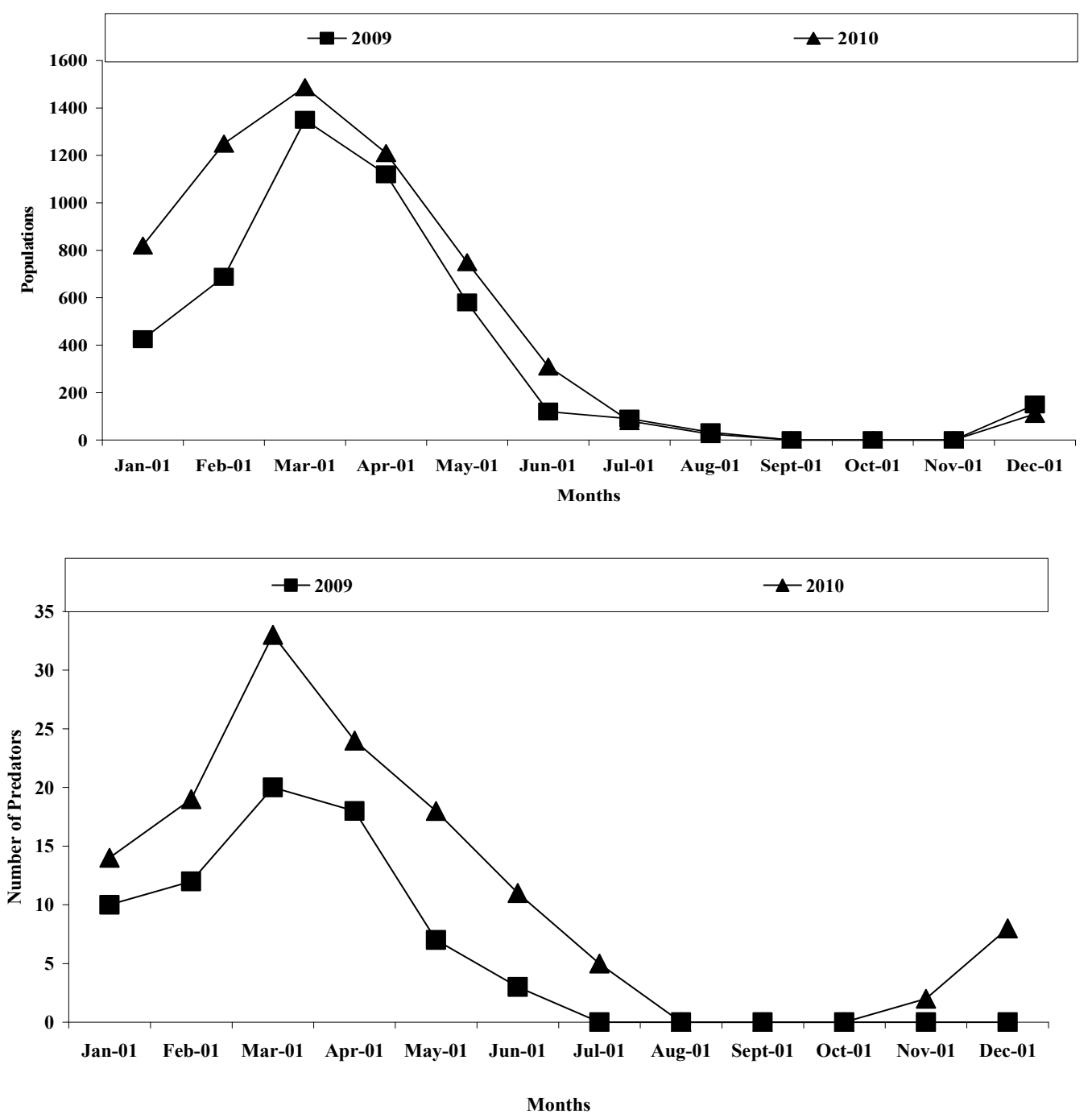

Fig. 10 : Number of indivduals of Orius sp. associated with the psyllid, Euphyllura straminea on olive trees in Fayoum Governorate

Statistical analysis showed that the simple correlation between the maximum, minimum temperature, relative humidity and the mean number of the predator, Orius sp. were significant $(\mathrm{r}=0.61,0.93,0.85$ and 0.65$)$, respectively and the mean number of the psyllid, $E u$. straminae during the 2009 year. Also, results showed that the simple regression for changing the maximum, minimum temperature, relative humidity and the mean number of the predator were significant $(b=0.69,0.91,0.88$ and 0.61$)$, respectively and the mean number of the psyllid, Eu. straminae during the 2009 year. In 2010, statistical analysis showed that the simple correlation between maximum, minimum temperature and the mean number of the predator were significant or highly significant $(r=0.89$ and 0.77$)$, respectively, and non- 
significant $(r=0.37$ and 0.28$)$ between the population of predator, relative humidity and the mean number of the psyllid during the 2010 year. Also, statistical analysis showed that the simple regression for changing maximum, minimum temperature and the mean number of the predator were significant $(r=0.94$ and 0.70$)$, respectively, and non-significant $(r=0.28$ and 0.31 ) between the population of predator, relative humidity and the mean number of the psyllid during the 2010 year.

6. Population dynamics of soft brown scale, Saissetia coffeae and its parasitoid and predator on olive trees in Northern Coast region.

The seasonal abundance of soft brown scale, Saissetia coffeae (Walker) (Hemiptera: Coccidae) was studied for two successive years from 2009-2010 on olive trees .The obtained results in Figs (11 and 12) showed that, the insect population reached maximum during October (2011 and 2250/ 60 leaves and 15 twigs) in the first and second years, respectively. Percent parasitism by Metaphycus flavus (Howard) (Hymenoptera: Encyrtidae) reached maximum during October during the first year (11.5/60 leaves and 15 twigs, respectively) and during September in the second year (13.5/60 leaves and 15 twigs, respectively). The predator, Scymnus syriacus (Marseul) (Coleoptera: Coccinellidae) reached maximum during October in the first and second years (36 and 40 individuals/ 60 leaves and 15 twigs, respectively).

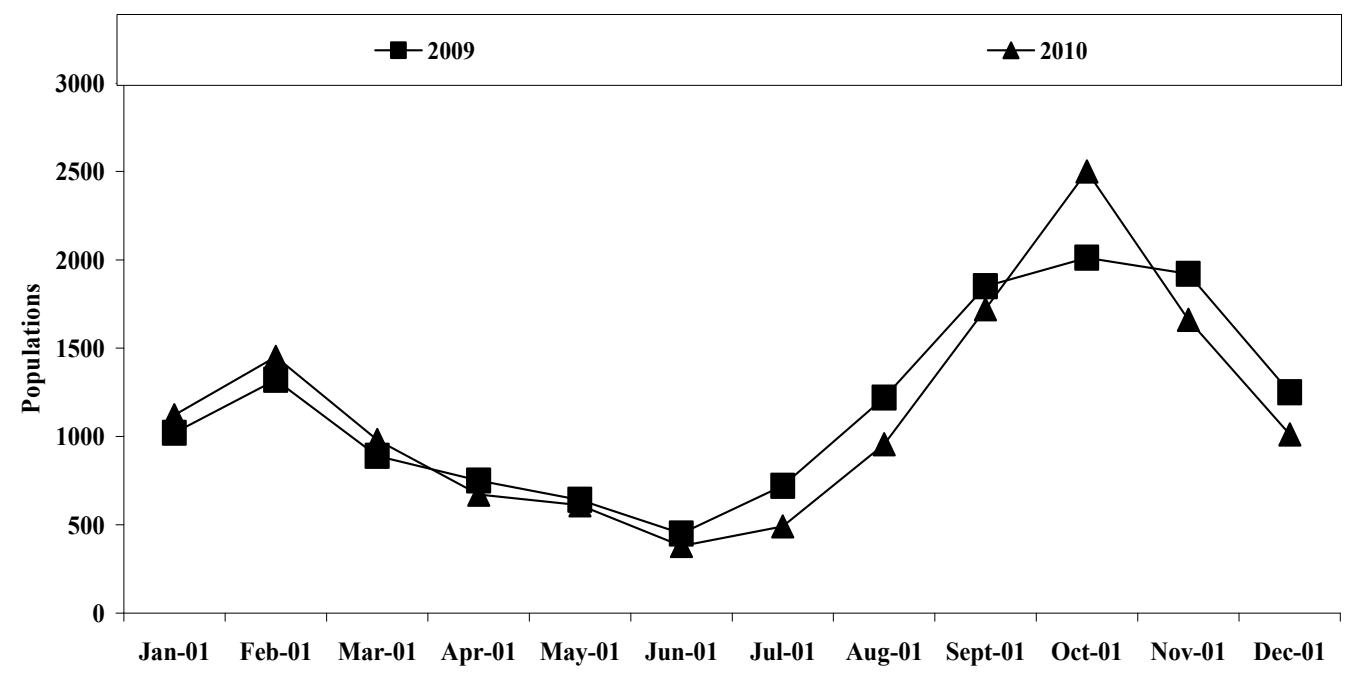

Months

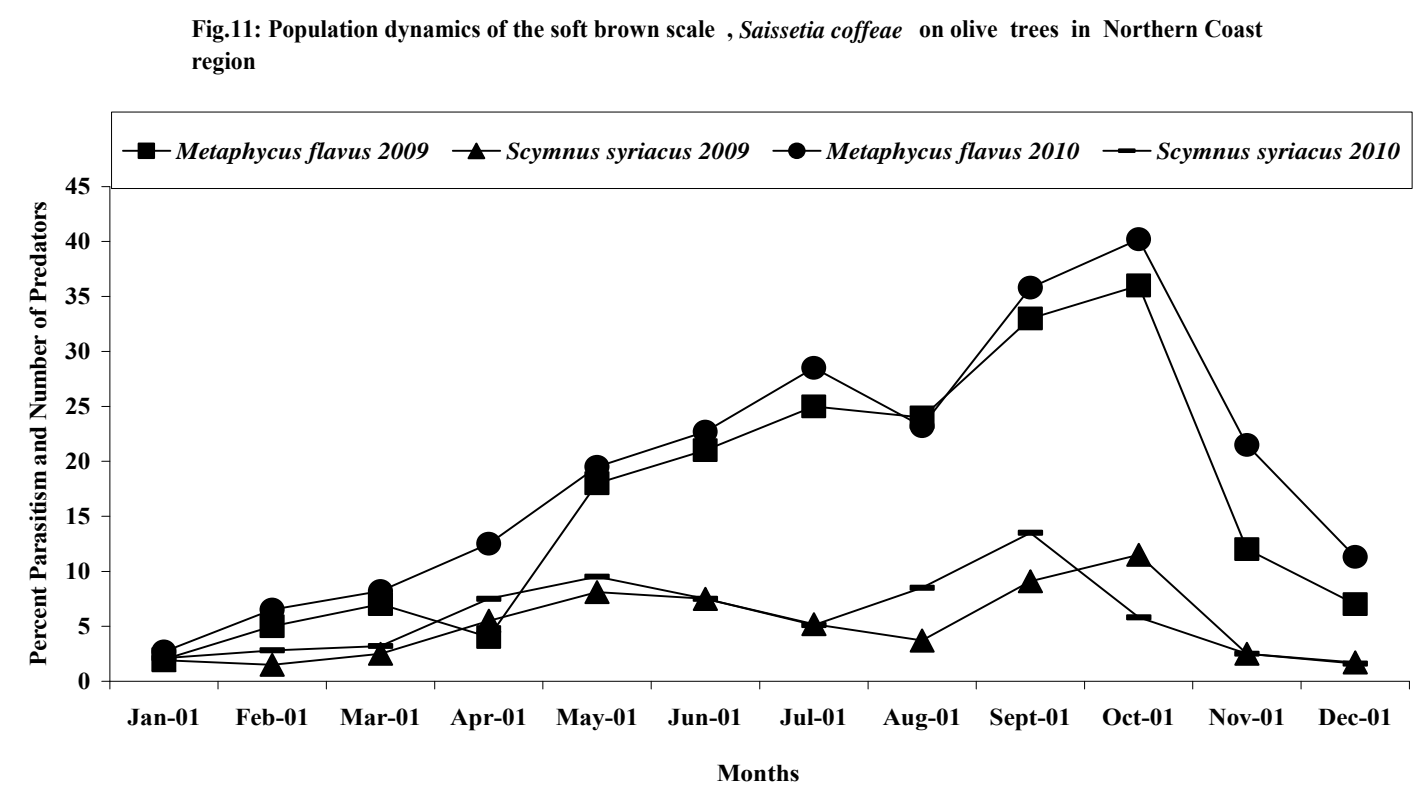

Fig. 12: Percent parasitism by different parasitoids and predator associated with the soft brown scale, Saissetia coffeae on olive trees in Northern Coast region 
Statistical analysis showed that the simple correlation between the population of the predator, $S$. syriacus, maximum, minimum temperature and the mean number of the soft brown scale, $S$. coffeae were significant $(\mathrm{r}=0.64,0.88$ and 0.71$)$, respectively and non-significant $(\mathrm{r}=0.28$ and 0.32$)$ between parasitoid, $M$. flavus, relative humidity and the mean number of the soft brown scale during the 2009 year. Also, statistical analysis showed that the simple regression for changing the population of predator, maximum, minimum temperature and the mean number of the soft brown scale, $S$. coffeae were significant $(\mathrm{b}=0.71,0.93$ and 0.81$)$, respectively and nonsignificant $(\mathrm{b}=0.35$ and 0.38$)$ between the parasitoid, relative humidity and the mean number of the soft brown scale during the 2009 year. In 2010, statistical analysis showed that the simple correlation between the population of predator, maximum, temperature and the mean number of the soft brown scale, S. coffeae were significant $(\mathrm{r}=0.74$, and 0.82$)$, respectively and non-significant $(\mathrm{r}=0.35,0.27$ and 0.16$)$ between parasitoid, minimum temperature, relative humidity and the mean number of the soft brown scale. Also, statistical analysis showed that the simple regression for changing the population of predator, maximum temperature and the mean number of the soft brown scale, $S$. coffeae were significant $(b=0.78$ and 0.95$)$, respectively and nonsignificant $(\mathrm{b}=0.29,0.25$ and 0.13$)$ between the parasitoid, minimum temperature, relative humidity and the mean number of the soft brown scale.

\section{Population dynamics of the Mediterranean soft scale, Saissetia oleae and its parasitoid and predator on olive trees in El-Arish region.}

The seasonal abundance of the Mediterranean soft scale, Saissetia oleae (Bernard) (Hemiptera: Coccidae) was studied for two successive years from 20092010 on olive trees. The obtained results in Figs (13 and 14) showed that, the insect population reached maximum during October (4520 and 5410/60 leaves and 15 twigs) in the first and second years, respectively.

Percent parasitism of Metaphycus lounsburyi (Howard) (Hymenoptera: Encyrtidae) reached maximum during October during the first and second years (34.2.1 and 40.1 / 60 leaves and 15 twigs, respectively). The predator Exochomus flavipes reached maximum during October in the first and second years (15 and 19 individuals / 60 leaves and 15 twigs, respectively).

Statistical analysis showed that the simple correlation between the population of parasitoid, maximum, minimum temperature and the mean number of the Mediterranean soft scale, $S$. oleae were significant or highly significant $(\mathrm{r}=0.62,0.91$ and 0.77$)$, respectively and non-significant $(\mathrm{r}=0.27$ and 0.22$)$ between predator, relative humidity and the mean number of the soft scale during the 2009 year. Also, statistical analysis showed that the simple regression for changing the population of parasitoid, maximum, minimum temperature and the mean number of the Mediterranean soft scale, S. oleae were significant $(\mathrm{r}=0.71,0.89$ and 0.81$)$, respectively and non-significant $(r=0.31$ and 0.19$)$ between predator, relative humidity and the mean number of the soft scale during the 2009 year. In 2010, statistical analysis showed that the simple correlation between the population of parasitoids, maximum, minimum temperature and the mean number of the Mediterranean soft scale, $S$. oleae were significant or highly significant $(r=0.66,0.94$ and 0.79$)$, respectively and non-significant $(r=0.18$ and 0.15$)$ between predator, relative humidity and the mean number of the soft scale. Also, statistical analysis showed that the simple regression for changing the population of parasitoid, maximum, minimum temperature and the mean number of the Mediterranean soft scale, S. oleae were significant $(\mathrm{r}=0.68,0.87$ and 0.72$)$, respectively and non- 
significant $(\mathrm{r}=0.21$ and 0.21$)$ between predator, relative humidity and the mean number of the soft scale.

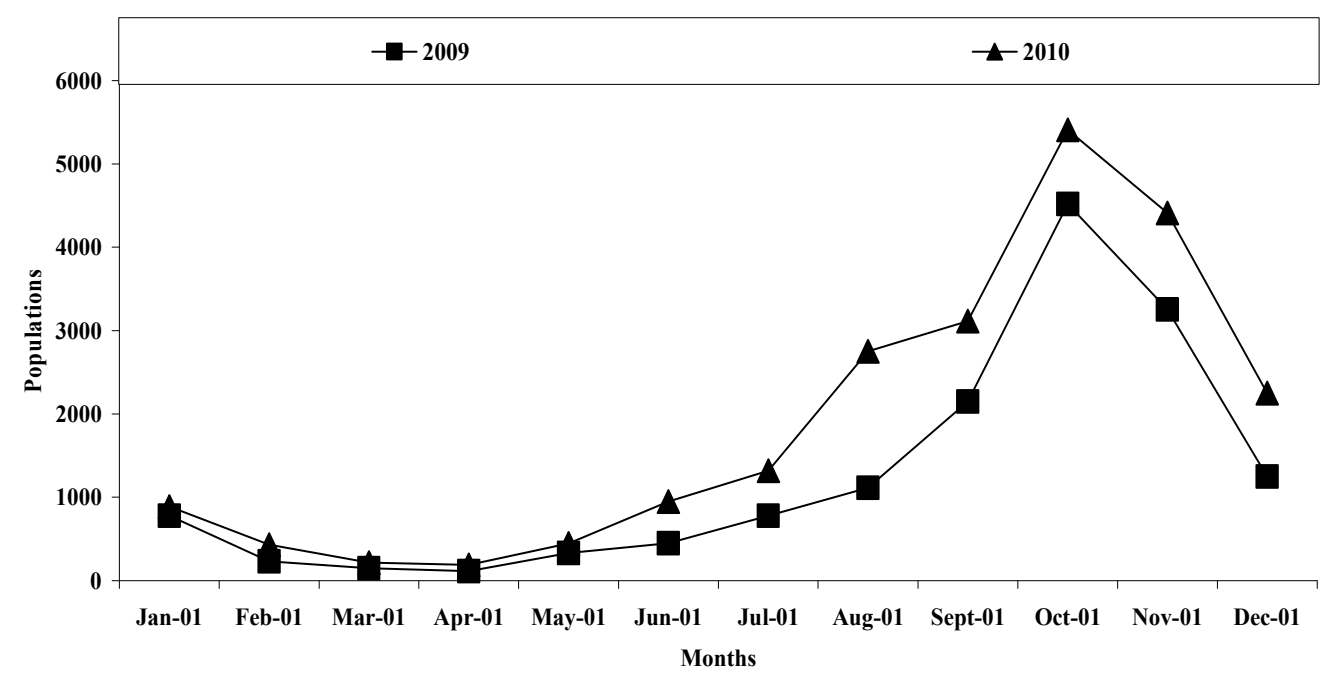

Fig.13: Population dynamics of the Mediterranean soft scale, Saissetia oleae on olive trees in Ismailia Governorate

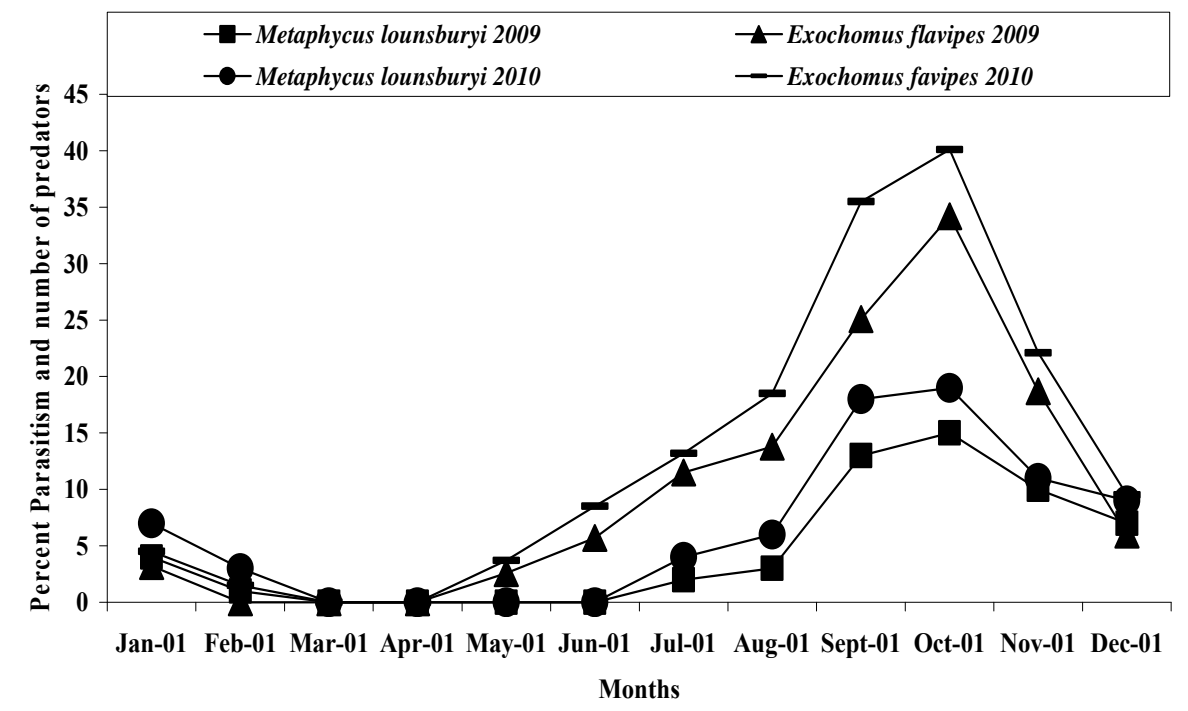

Fig. 14: Percent parasitism by different parasitoids and the number of predator associated with the Mediterranean soft scale, Saissetia oleae on olive trees in Ismailia Governorate

The results of the present work indicated that the seasonal abundance of the olive scale, L. riccae on olive trees reached maximum during November and February in first and second years, respectively. The study of the population densities of diaspidids showed that $L$. riccae had 4 population peaks in Tora and Fayoum and 3 in Alexandria (El-Hakim and Helmy, 1982). L. riccae differed in susceptibility to it were observed between different olive cultivars. L. riccae had 2 overlapping generations a year (Moursi and Hegazi, 1983). The common scale insect pests which were found on leaves, branches and fruits throughout the year were the 4 diaspidids including $L$. riccae. The population fluctuations of these 4 diaspidids were studied between February and May (Moursi and Mesbah, 1985). Parasitism by a species of Aphytis was observed only during the rainy season, when relative humidity was high; it thus 
had little influence in regulating populations of L. riccae on rain-fed olive (Moursi and Hegazi, 1985). The aphelinid parasitoid Aphytis sp. was found attacking L. riccae (Moursi and Mesbah, 1985 and El-Khawas et al., 2000). While Percent parasitism by A. libanicus reached maximum during December with percent parasitism 11.1 and $12.2 \%$ respectively during the two years under considerations of our work. $P$. oleae had 3 peaks in Tora and Fayoum and 2 in Alexandria. The scale insects migrated from the leaves to the fruits at the beginning of July (El-Hakim and Helmy, 1982). Population fluctuations of $P$. oleae was studied in two regions of Assiut Governorate (Sahel-Selim and Assiut College Farm). The pest population decreased gradually from January till April and then increased to reach its maximum level of abundance in September in Sahel-Selim. The average mean number of $P$. oleae was 512.83 and 626.5 individuals/50 leaves during the two years under consideration, respectively. Approximately, the same trend occurred in Assiut College Farm, except that the population of the pest was very low compared with that at Sahel-Selim (AbouElhagag, 2004). But here the insect population of the parlatoria scale, P. oleae reached maximum during October in Ismailia governorate. During this work percent parasitism by $A$. lingnanensis and $H$. aspidioti reached maximum during December and November with percent parasitism 6.5 and 12.5 in the first year, respectively and in November in the second year with percent parasitism 6.9 and $14.2 \%$ While the predator C. bipustulatus reached maximum during February and March in the first and second years. Abd-Rabou (2001a) recorded the aphelinid parasitoids, Aphytis paramaculicornis, A. chrysomphali (Hymenoptera: Aphelinidae) and Encarsia aurantii (Hymenoptera: Aphelinidae) in olive groves infested with P. oleae at five locations in Egypt. Also In this work the abundance of soft brown scale, S. coffeae reached maximum during October in the first and second years. Percent parasitism by $M$. flavus reached maximum during October and September with parasitism rates 11.5 and $13.5 \%$ during the first second years, respectively. The predator, S. syriacus reached maximum during October in the first and second years. Abdel-Rahman (1995) stated that $S$. coffeae is the main species of hemipterans attacking olive trees. S. coffeae had three generations, during April-May, June-July and August-September. The third generation overwinters as second nymphal instar from November till February (El-Minshawy and Saad, 1976). While Hanafi in the same year recorded 3-4 peaks for this soft scale. A total of about 300,000 individuals of the parasitoid Coccophagus cowperi Girault (Hymenoptera: Aphelinidae), obtained from India, was released at 35 sites for the biological control of S.coffeae on olive trees in Egypt. The maximum parasitism rates reached 53 and $62 \%$, while average parasitism rates were 17.2 and $30.8 \%$ in the Marsy Mattrouh and El-Arish locations, respectively. These results indicate establishment of this parasitoid on this important economic plant in Egypt (Abd-Rabou, 2005). The populations of the Mediterranean soft scale, S.oleae reached maximum during October in the first and second years. Percent parasitism of $M$. lounsburyi reached maximum during October during the first and second years with percent parasitism 34.2.1 and 40.1\% respectively (Abd-Rabou, 2004a,b). The predator E. flavipes reached maximum during October in the first and second years. Abd-Rabou (1999) observed S. oleae is an important pest of olive trees in Egypt. A survey of the parasitoids of S. oleae was carried out monthly between April 1995 and March 1997 in three different locations (Northern coast, Matruh and El-Arish) in Egypt. Abd-Rabou (2004a) recorded five species of Encyrtidae (Diversinervus elegans, M. flavus, M. zebratus and 2 other species of Metaphycus), a species of Pteromalidae (Scutellista caerulea) and an aphelinid hyperparasite (Marietta leopardina) were found. The two Metaphycus spp. and M. leopardina were new 
records for Egypt. The Mediterranean black scale, S. oleae is the most important pest of olive in Egypt. Indigenous parasitoids of S. oleae from different localities were collected, reared, mass produced and released for augmentative biological control (Abd-rabou, 2001a). The population dynamics of the five hymenopterus parasitoids, i.e. $M$. bartletti, $M$. flavus, Microterys flavus, D. elegans and S. cyanea, were studied in a Northern Coast site during 1998-99 and 1999-2000 (Abd-Rabou, et al., 2003). M. bartletti was the most effective parasitoid of Saissetia oleae on olive trees with maximum rates of parasitism of 23.0 and $24.5 \%$ during the two years under considerations, respectively. The population dynamics of 6 predators were studied at the same site. Two peaks were recorded annually for $C$. bipustulatus, $C$. carnea and C. undecimpunctata, and S.syriacus. E. flavipes and Orius sp. were recorded at low populations throughout the study. This work observed the seasonal abundance of the olive whitefly, A. olivinus reached maximum during April in first and second years. While AbdRabou (2003a) stated that A.olivinus has only one generation per year. Adults are active in June and July. Natural enemies usually suffice to keep populations of this whitefly at a very low level. Percent parasitism by E.olivina reached maximum during April during the first and second years with percent parasitism 0.6 and 0.5 , respectively. This species was recorded for the first time in Egypt by Abd-Rabou (2000) and collected in a few numbers (Abd-Rabou, 2006). The abundance of the whitefly, S. phillyreae here reached maximum during October in first and second years, respectively. Percent parasitism reached maximum during October in first and second years with percent parasitism 1.8 and 2.9\%, respectively. This species was recorded for the first time in Egypt by Abd-Rabou (2003a). The results of the present study indicated that the seasonal abundance of the psyllid, E. straminae reached maximum during March in the first and second years. While Elwan (2001) stated that the seasonal abundance of Eu. straminea on olives was investigated. The effect of weather parameters on psyllids populations was also evaluated. The first and second instars nymphs appears in November or Early December until late June and were most abundant in March or April. The third and fourth instars appears in December-January and January, respectively, and are abundant in April. The adults occurs the whole year, and are abundant in April. Weather factors were found to be significantly and negatively correlated with nymphal and adult populations, respectively. Natural enemies, including lady beetles, lacewing, small predaceous bugs, and parasitic wasps which attack only certain psyllids, provide at least partial control of all psyllids (Dahlsten et al.1995 and 1998). Psyllid natural enemies should be conserved by using appropriate cultural practices and only low toxicity, short-persistence pesticides, or whenever possible, inject insecticides instead of spraying if direct control action is needed. Several introduced species of natural enemies now occur naturally throughout different countries of the world. Also here the predator Orius sp. reached maximum during March in the first and second years with little effect of this pest.

\section{REFERENCES}

Abdel-Rahman, A G. (1995): Seasonal abundance of some pests attacking olives and their control under El-Qasr conditions, Matrouh Governorate. Annals-ofAgricultural-Science,-Moshtohor. 33(4): 1553-1564.

Abd-Rabou, S. (1996): Egyptian Aleyrodidae. Acta Phytopathologica et Entomologica Hungarica, 31 (3-4): 275-285.

Abd-Rabou, S. (1997): Hosts, distribution and vernacular names of whiteflies (Homoptera : Aleyrodidae) in Egypt. Annals of Agric. Sci., Moshtohor, 35 (2): 1029-1048.

Abd-Rabou, S. (1999): Parasitoids attacking the Mediterranean black scale, Saissetia oleae (Hemiptera: Coccidae) on olive in Egypt. Entomologica-. 33: 169-172.

Abd-Rabou, S. (2000): Newly recorded of aphelinids and encyrtids in Egypt. Egypt. J. Agric. Res. 78 (5): 1915-1924. 
Abd-Rabou, S. (2001a): Biological control of the Mediterranean black scale Saissetia oleae (Olivier) (Hemiptera: Coccidae) on olive in Egypt. Bollettino-di-ZoologiaAgraria-e-di-Bachicoltura. 33(3): 483.

Abd-Rabou, S. (2001b): The effect of augmentative releases of indigenous parasitoids on populations of Parlatoria oleae (Colvee) (Hemiptera: Coccoidea) in olive groves in Egypt. Bollettino-di-Zoologia-Agraria-e-di-Bachicoltura. 33(3):473-481.

Abd-Rabou, S. (2003a): First record of pomegranate whitefly, Siphoninus phillyreae (Haliday) (Homoptera: Aleyrodidae) on olive in North Sinai, Egypt. EgyptianJournal-of-Agricultural-Research. 81(4): 1577-1579.

Abd-Rabou, S. (2003b): Scale insects and their management in Egypt. Adv. Agric. Res. In Egypt, 4(1): 1-63.

Abd-Rabou, S. (2004a): Augmentative releases of indigenous parasitoids of the Mediterranean black scale Saissetia oleae (Oliver) (Hemiptera: Coccidae) on olive in Egypt. Shashpa-11(1): 51-56.

Abd-Rabou, S. (2004b): The role of augmentative releases of indigenous parasitoid Metaphycus lounsburyi (Hymenoptera: Encyrtidae) in enhancing the biological control of Saissetia oleae (Homoptera: Coccidae) on olive in Egypt.Archives-ofPhytopathology-and-Plant-Protection. 37(3): 233-237.

Abd-Rabou, S. (2005): Importation, colonization and establishment of Coccophagus cowperi Gir. (Hymenoptera: Aphelinidae) on Saissetia coffeae (Walk.) (Homoptera: Coccidae). in Egypt Journal-of-Pest-Science. 78(2): 77-81.

Abd-Rabou, S. (2006):Hymenopterous parasitoids as a bioagent for controlling homopterous insects in Egypt. Egypt. Adv. Agric. Res. In Egypt, 6 (1): 1-65.

Abd-Rabou, S. (2008): Olive Pests and Their Integrated Management in Egypt Adv. Agric. Res. In Egypt, 8(1): 1-41.

Abd-Rabou, S., Hafez, A. and Badary, H. (2003): Survey and dynamics of natural enemies of the Mediterranean Black Scale, Saissetia oleae (Hemiptera: Coccidae) in Egypt. Egyptian J. of Agric. Res. 81(1): 115-123.

Abou-Elhagag, G. H. (2004): Abundance of olive scale insect, Parlatoria oleae Clovee (Homoptera: Diaspididae) and its parasitoids in Upper Egypt. Assiut-Journal-ofAgricultural-Sciences. 35(3): 197-208.

Amin, A. R. H. (1966): Biological and ecological studies on the olive scale, Parlatoria oleae (Clovee) in Egypt (Homoptera: Coccoidea). M. Sc. Thesis, Fac. of Agric., Ain Shams Univ., Egypt.

Amin, A.H. and Saleh, M. R. A. (1975): Seasonal activity of the olive leaf moths, Palpita unionalis (Hbuner) (Lepidoptera: Pyralidae), in Kharga-Oasis, New- Vally, Egypt. Ann. of Agric. Sci., Fac. Agric., Ain Shams Univ. 20 (1): 35- 41.

Dahlsten, D. L., Kent, D. M., Rowney, D. L., Copper, W. A., Young, T. E., and Tassan, R. L. (1995): Parasitoid shows potential for biocontrol of eugenia psyllid. Calif. Agric. 49(4):36-40.

Dahlsten, D. L., Rowney, D. L., Copper, W. A., Tassan, R. L., Chaney, W. E., Robb, K. L., Tjosvold, S., Bianchi, M. and Lane, P. (1998): Parasitoid wasp controls blue gum psyllid. Calif. Agric. 52(1):31-34.

Dreistadt, S. H., Clark, J. K. and Flint, M. L. (1994): Pests of Landscape Trees and Shrubs: An Integrated Pest Management Guide. Oakland: Univ. Calif. Agric. Nat. Res. Publ. 3359.

El-Hakim, A. M and Helmy, E.I. (1982): Survey of and population studies on olive leaf pests in Egypt. Bulletin-de-la-Societe-Entomologique-d'-Egypte. (64): 213-220.

El-Khawas, M.A; El-Heneidy,A.H; Omar,A.H and El-Sherif, H. (2000): A recent record of parasitoids on common olive pests in Egypt.Egyptian-Journal-of-BiologicalPest-Control. 10(1/2): 137-138. 
Elwan, E.S.A.H. (2001): Ecological studies on the olive psyllid, Euphyllura straminea Loginova (Homoptera:Psylloidea: Aphalaridae) in Al-Arish, North Sinai, Egypt. Egyptian-Journal-of-Agricultural-Research. 79(1): 161-178.

Ezzat, Y. M. (1957): Biological studies on the olive scale, Parlatoria oleae (Clovee). Bull. Entom. Egypte. 41: 351.

Gill, R. J. (1997): The Scale Insects of California Parts 1-3. Sacramento: Calif. Dept. Food Agric.

Hamza, M. M. (1975): Studies on certain insect pests attacking olive trees. M. Sc. Thesis, Fac. of Agric., Alexandria Univ., Egypt.

.Moursi, K.S and Hegazi, E.M. (1983): The olive-tree scale, Leucaspis riccae Targ. (Hom.; Diaspididae) as a key pest of olive trees in dry farm system in the Egyptian western desert .Bollettino-del-Laboratorio-di-Entomologia-Agraria-'Filippo-Silvestri', 40: 119-124.

Moursi, K. S. and Mesbah, H. A. (1985): Olive pests of irrigated farm system in the Egyptian western desert with special references to armoured scale insects. Annals of Agric. Sci., Moshtohor. 23 (2): 901- 911.

Solaiman, A. F. (1970): Studies on the morphology, biology and control of certain coccids in Egypt. M. Sc. Thesis, Fac. of Agric., Ain Shams Univ., Egypt 318pp.

\section{ARABIC SUMMARY}

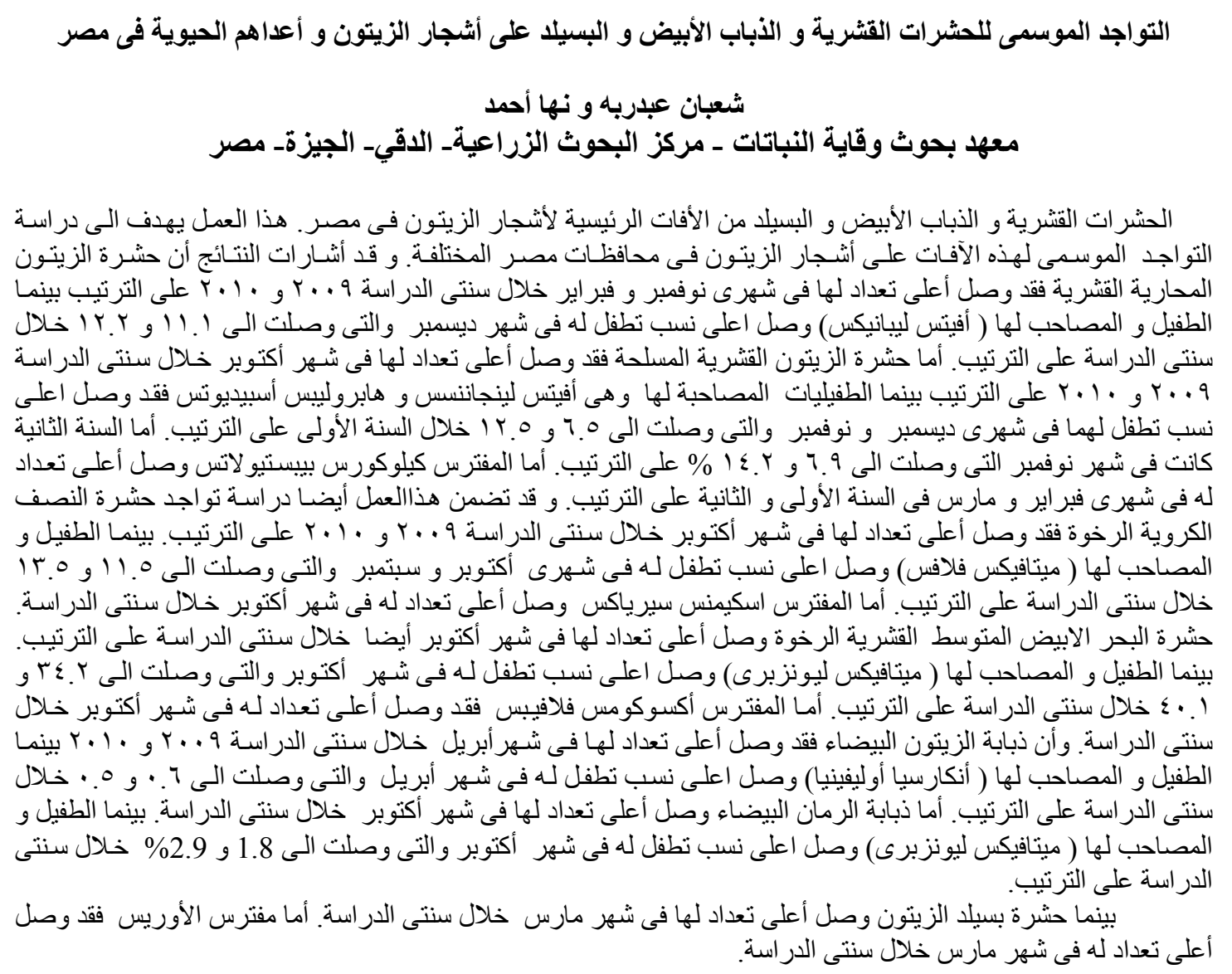

